\title{
Selective conversion of various monosaccharaides into sugar acids by additive-free dehydrogenation in water
}

\author{
Andres Mollar-Cuni, ${ }^{[a]}$ Joseph P. Byrne, ${ }^{[b]}$ Pilar Borja, ${ }^{[a]}$ Cristian Vicent, ${ }^{[c]}$ Martin Albrecht, ${ }^{[b]}$ and Jose A. \\ Mata ${ }^{*}[a]$
}

[a] A. Mollar-Cuni, Dr. P. Borja and Dr. J. A. Mata

Institute of Advanced Materials (INAM), Centro de Innovación en Química Avanzada (ORFEO-CINCA)

Universitat Jaume I

Avda. Sos Baynat s/n, 12006, Castellón, Spain

E-mail:jmata@uji.es

@inam_uji

[b] Dr. J. P. Byrne and Prof. Dr. M. Albrecht

Department of Chemistry \& Biochemistry.

University of Bern

Freiestrasse 3, 3012. Bern, Switzerland

E-mail: martin.albrecht@dcb.unibe.ch

@albrecht_lab

[c] Dr. C. Vicent

Servei Central d'Instrumentació Científica (SCIC)

Universitat Jaume I

Avda. Sos Baynat s/n, 12006, Castellón, Spain

Supporting information for this article is given via a link at the end of the document.

\begin{abstract}
Abundant sugars of five and six carbon atoms are promising candidates for the production of valuable platform chemicals. Here, we describe the catalytic dehydrogenation of several pentoses and hexoses into their corresponding sugar acids with the concomitant formation of molecular hydrogen. This biomass transformation is promoted by highly active and selective catalysts based on iridium-(III) complexes containing a triazolylidene (trz) as ligand. Monosaccharides are converted into sugar acids in an easy and sustainable manner using only catalyst and water, and in contrast to previously reported procedures, in the absence of any additive. The reaction is therefore very clean, and moreover highly selective, which avoids the tedious purification and product separation. Mechanistic investigations using ${ }^{1} \mathrm{H}$ NMR and UV-vis spectroscopies and ESI mass spectrometry (ESI-MS) indicates the formation of an unprecedented diridium-hydride as dormant species that correspond to the catalyst resting state.
\end{abstract}

\section{Introduction}

Biomass represents an abundant and natural renewable feedstock for the preparation of initial platform chemicals. ${ }^{[1-4]}$ The growing interest in the production of bio-sourced chemicals lies in the circular character of carbon which represents a neutral carbon process. Replacing the use of fossil fuels with transformation of biomass is a major challenge for reduction of global $\mathrm{CO}_{2}$ emissions. ${ }^{[5-9]}$ The initial platform chemicals obtained from biomass are sustainable intermediates for the production of specific chemicals. ${ }^{[10-13]}$ Carbohydrates are abundant in nature and constitute one of the major components of plant biomass. ${ }^{[14,15]}$ Among them, monosaccharides of five and six carbon rings are the basic units of cellulose and hemicellulose. Conversion of these sugars, particularly D-Glucose and D-Xylose, represents an interesting biomass source for the preparation of initial platform chemicals. ${ }^{[16-20]}$ Oxidation of sugars into the corresponding sugar acids produces useful chemical intermediates with applications in food, pharmaceutical and other specific industries. Traditionally, oxidation of sugars is carried out by enzymatic or heterogeneous catalysts. ${ }^{[21,22]}$ The main limitation for these approaches is a rigorous control of the reaction conditions to avoid $\mathrm{pH}$ variations, oxygen pressure and stability of the natural catalysts. For the conversion of sugars, there is a need to develop selective transformations avoiding tedious separation or purification techniques. Unsurprisingly, therefore, the majority of catalysts for the conversion of carbohydrates is restricted to materials and enzymes. The use of homogeneous catalysts for the conversion of sugars is scarce even though these types of catalysts generally lead to highly selective transformations. ${ }^{[23,24]}$ One of the reasons for this underdeveloped chemistry is the often poor stability and solubility of well-defined organometallic species in aqueous media. However, recent developments have indicated substantial progress of organometallic chemistry in water, ${ }^{[25-28]}$ thus providing new opportunities for biomass transformation in aqueous media with homogeneous catalysts.

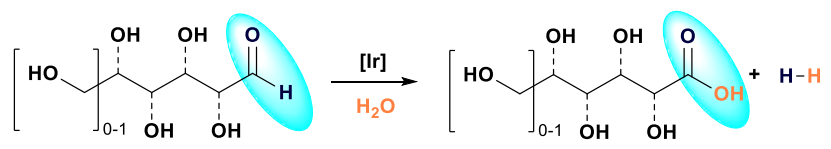

Figure 1. Selective dehydrogenation of sugars into sugar acids without additives.

Prompted by this expansion of organometallic chemistry into aqueous media, we decided to explore the potential of iridium complexes as homogeneous catalysts for the conversion of glucose. In preliminary work, we demonstrated the formation of gluconic acid using homogeneous $\mathrm{Cp}^{*} \mathrm{Ir}$ complexes with 
imidazole-based $\mathrm{N}$-heterocyclic carbene (NHC) ligands. ${ }^{[29]}$ This transformation is formally an oxidation of glucose but is better described as a dehydrogenative coupling of glucose and water with the simultaneous formation of molecular hydrogen. Starting from glucose, the process is highly selective towards the formation of gluconic acid but requires strong acidic conditions. In this context, modulation of well-defined organometallic species with suitable ligands offers an attractive methodology to increase activity and selectivity in the activation of functional groups. Here, we demonstrate that the introduction of triazolylidene (trz) ligands induces a substantial improvement of the catalytic properties of these iridium complexes in the conversion of sugars into sugar acids (Figure 1). The enhanced catalytic competence allows to omit the harsh acid additives and significantly broadens the substrate scope to efficient dehydrogenative coupling of other carbohydrates. Moreover, this approach provided relevant mechanistic insights into this transformation.

\section{Results and Discussion}

The catalytic conversion of sugars into sugar acids was tested using a series of $\mathrm{Cp}^{*} \operatorname{Ir}($ carbene $) \mathrm{Cl}_{2}$ complexes containing different carbene ligands (Figure 2). Complex 1, containing an Arduengo-type $\mathrm{N}$-heterocyclic carbene ligand (NHC), was used for comparative purposes. Complexes 2-4 contain a triazolederived ligand with different substituents that modulate the electronic and the steric properties. The triazolylidene ligands do not possess a neutral resonance structure and are therefore more polar. Moreover, iridium trz complexes were observed to be highly water-soluble, ${ }^{[30,31]}$ which may be due in parts to the polar structure, and in other parts due the presence of a backbone nitrogen for potential hydrogen bonding. ${ }^{[32]}$ Complex 4 contains a carbohydrate wingtip group which has been introduced to probe whether hydrogen bonding to sugar substrates favours the catalytic process.
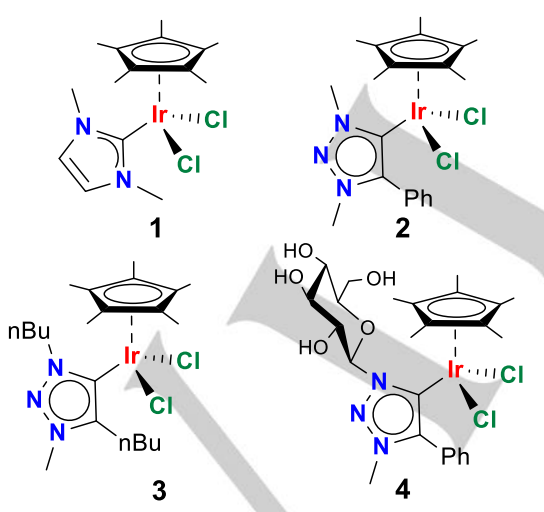

Figure 2. Iridium complexes used in the catalytic dehydrogenation of sugars featuring an NHC ligand (1) and triazolylidene (trz) ligands (2-4), respectively.

In a first set of experiments, we evaluated the catalytic activity of complexes 1-4 in the conversion of glucose to gluconic acid. The experimental set-up consists of the addition of the iridium complex to a solution of glucose in deionised water. The mixture is heated at reflux and the progress of the reaction and selectivity is monitored by NMR spectroscopy and HPLC chromatography. As a representative example, the reaction progress for the conversion of glucose to gluconic acid was profiled using complex 2 as catalyst precursor (Figure 3a). The mass balance confirms that all glucose is converted to gluconic acid. Product analysis by NMR spectroscopy and MS does not show the formation of any other by-products. Interestingly, and contrary to our previous observations using complex $\mathbf{1}$, complex 2 performs better without additives. $A>90 \%$ conversion of glucose is observed without the addition of $\mathrm{H}_{2} \mathrm{SO}_{4}$ after $7.5 \mathrm{~h}$. In contrast, the addition of acid $(0.25$ equiv.) reduced the conversion to $65 \%$ (Figure $3 \mathrm{~b}$ ).

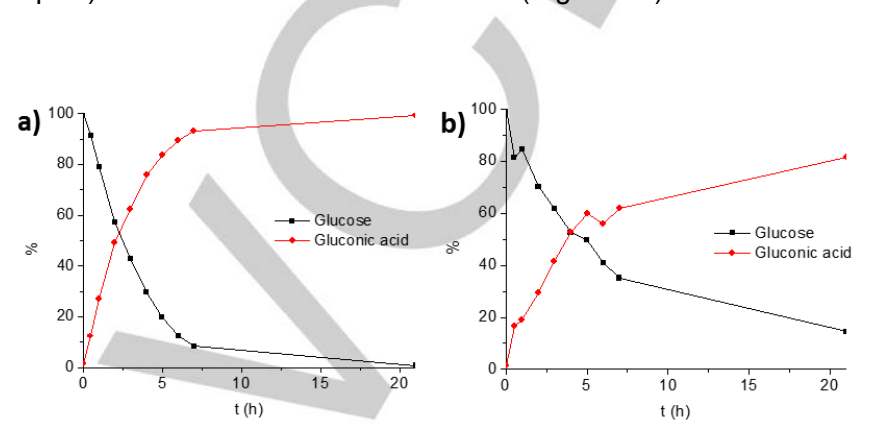

Figure 3. Reaction profile monitored by HPLC-MS/MS of glucose conversion (black squares) and gluconic acid formation (red diamonds) using catalytic quantities of complex $2(2 \mathrm{~mol} \%)$ at $110^{\circ} \mathrm{C}$ (bath temperature). Glucose $(0.44$ $\mathrm{mmol}$ ) in $20 \mathrm{~mL} \mathrm{H} \mathrm{H}_{2}$ : a) without additives and b) with 0.25 eq. of $\mathrm{H}_{2} \mathrm{SO}_{4}$.

These results prompted us to study the catalytic activity of $\mathbf{1 - 4}$ in the conversion of glucose to gluconic acid with and without additives (Table 1). Control experiments revealed that the presence of iridium complexes is required for the production of gluconic acid and hydrogen. We have not observed uncatalysed sugar degradation under neutral or acidic conditions at $110{ }^{\circ} \mathrm{C}$ (Table 1, entry 1). Monitoring substrate conversion over time using catalyst $\mathbf{4}$ showed high initial rates that, however, rapidly slowed down. This is an indication of catalyst deactivation by limited stability (Figures S4 and S5). In order to study the process of catalyst deactivation we performed thermal stability tests by ${ }^{1} \mathrm{H}$ NMR spectroscopy. Solutions of complex 2 and $\mathbf{3}$ in $\mathrm{D}_{2} \mathrm{O}(10 \mathrm{mM})$ are stable at $100{ }^{\circ} \mathrm{C}$ for at least $2 \mathrm{~h}$ without noticeable decomposition whereas complex $\mathbf{4}$ completely decomposes under these conditions into undefined products. Reducing the temperature to $80{ }^{\circ} \mathrm{C}$ increases stability and we have not observed degradation for up to $1 \mathrm{~h}$. These results show that catalyst $\mathbf{2}$ and $\mathbf{3}$ containing alkyl or aryl $\mathrm{N}$-substituents are stable at the optimal catalytic conditions but catalyst $\mathbf{4}$ decomposes rapidly, which accounts for the drop in catalytic activity of this complex. Conversion of glucose at lower temperatures $\left(80^{\circ} \mathrm{C}\right)$ is feasible, though requiring longer reaction times to achieve full conversion (Table 1, entry 6). 
Table 1. Glucose dehydrogenation using catalysts $\mathbf{1 - 4}$.

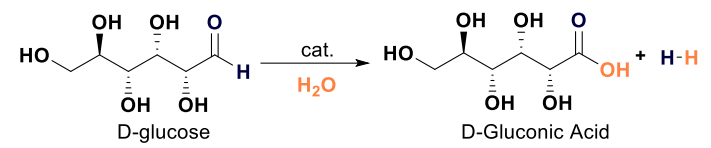

\begin{tabular}{|c|c|c|c|c|c|}
\hline Entry & Cat. & $\begin{array}{c}\text { Additive } \\
\mathrm{H}_{2} \mathrm{SO}_{4} \text { (Eq.) }\end{array}$ & $\begin{array}{c}\mathrm{T} \\
\left({ }^{\circ} \mathrm{C}\right)\end{array}$ & $\begin{array}{c}\begin{array}{c}\text { Conv } \\
(\%)^{\mathrm{a}}\end{array} \\
\end{array}$ & $\begin{array}{l}\text { Yield } \\
(\%)^{a}\end{array}$ \\
\hline 1 & - & - & 110 & - & - \\
\hline $2^{b}$ & 1 & - & 110 & 44 & 44 \\
\hline $3^{b}$ & 1 & 0.25 & 110 & 88 & 88 \\
\hline 4 & 2 & - & 110 & 100 & 100 \\
\hline 5 & 2 & 0.25 & 110 & 81 & 81 \\
\hline 6 & 2 & - & 80 & 90 & 71 \\
\hline 7 & 3 & - & 110 & 71 & 67 \\
\hline 8 & 4 & - & 110 & 35 & 33 \\
\hline 9 & 4 & 0.25 & 110 & 51 & 45 \\
\hline
\end{tabular}

Reaction conditions: Glucose ( $80 \mathrm{mg}, 0.44 \mathrm{mmol})$, catalyst loading ( $2 \mathrm{~mol} \%)$, deionised $\mathrm{H}_{2} \mathrm{O}(20 \mathrm{~mL})$ for $20 \mathrm{~h}$. [a] Conversions and yields determined by ${ }^{1} \mathrm{H}$ NMR spectroscopy and HPLC-MS/MS. [b] Data from reference 29.

In view of the excellent conversion of glucose to gluconic acid by dehydrogenation we decided to explore the catalytic activity of complexes 1-3 towards other C5 and C6 sugars (Table 2). A range of pentoses (D-ribose, D-xylose and L-arabinose), hexoses (D-mannose and D-galactose) as well as 2-deoxy-D-glucose are converted in water to the corresponding sugar acids by dehydrogenation with the formation of molecular hydrogen. The formation of hydrogen was qualitatively analysed by gas chromatography using a TCD detector. The set-up for the catalytic experiments only requires the addition of the catalysts into an aqueous solution of the carbohydrate. However, it is important to note that the reaction mixture should be maintained under constant reflux in an open system, since the continuous release of hydrogen from the reaction mixture facilitates conversion to the sugar. The reaction is not sensitive to the presence of oxygen indicating the high stability of catalysts under the reaction conditions. Catalysts 1-3 are highly active in the production of sugar acids, the isolated yields are $>90 \%$ in most cases. As noted for glucose conversion, complex 1 requires the addition of additives for better catalytic performance, which compromises yields to some extent. In contrast, no additives are necessary when employing complexes $\mathbf{2}$ and $\mathbf{3}$ containing a triazolylidene ligand, and isolation of the product is therefore particularly simple. Analysis of the crude product by ${ }^{1} \mathrm{H}$ NMR spectroscopy revealed highly selective oxidation of the $\mathrm{C} 1$ position and clean formation of the corresponding sugar acids and therefore, no further purification was required (See ESI for detailed procedures and characterisation). Of note, product analysis in the case of Dglucose or D-xylose by NMR spectroscopy under neutral or acidic conditions is complicated by the presence of different species due to the acid/base equilibria coupled with partial lactonisation. However, in basic media, these equilibria are shifted and only one set of signals is observed.

Table 2. Reaction scope. Conversion of pentoses and hexoses into sugar acids.

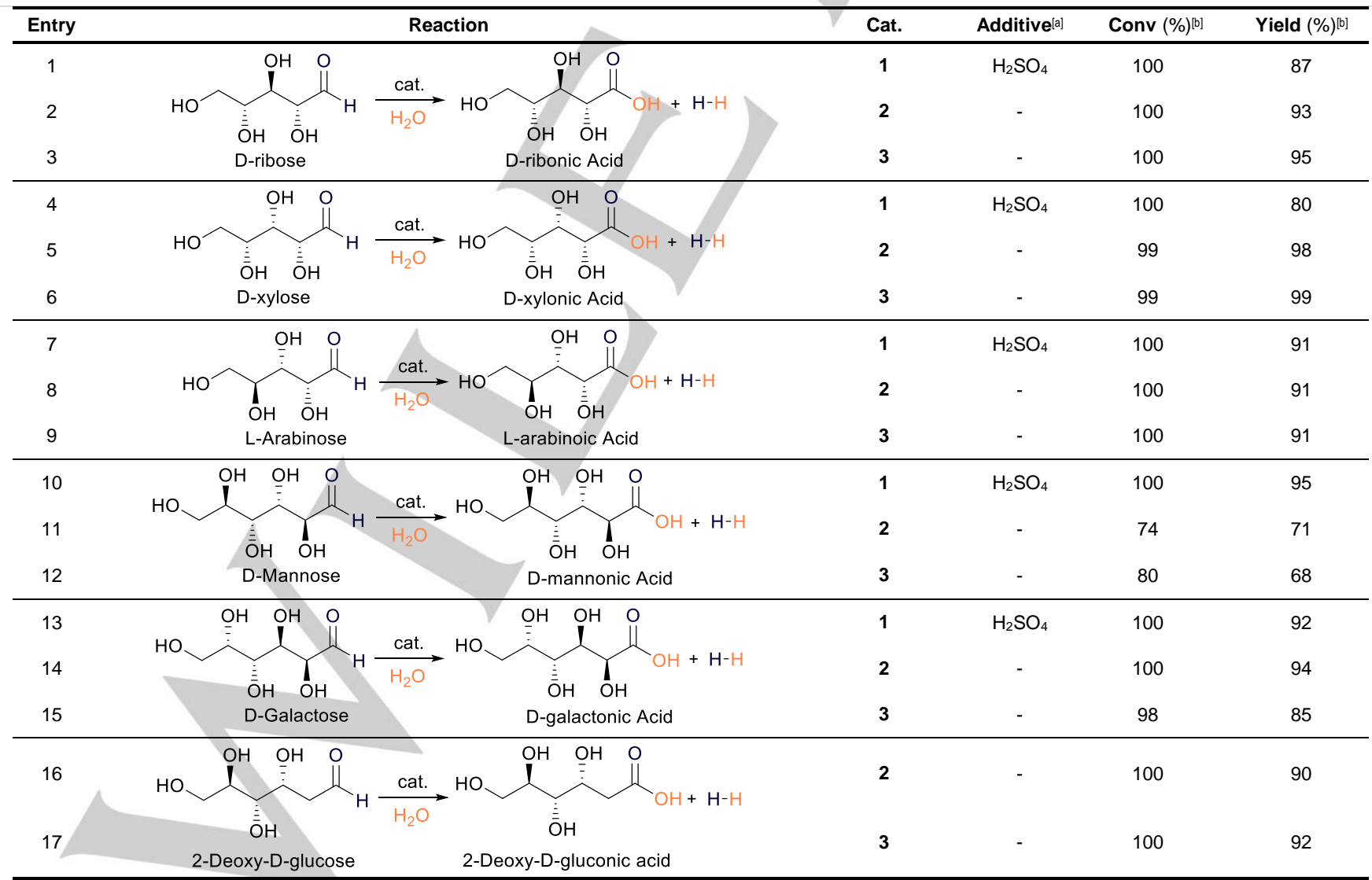

Reaction conditions: Sugar $(0.44 \mathrm{mmol})$, catalyst loading $(2 \mathrm{~mol} \%)$, deionised $\mathrm{H}_{2} \mathrm{O}(5 \mathrm{~mL})$ at $110{ }^{\circ} \mathrm{C}$ for $20 \mathrm{~h}$. [a] Additive 0.25 eq. [b] conversions and yields determined by ${ }^{1} \mathrm{H}$ NMR spectroscopy and HPLC-MS/MS for selected experiments. 
Monitoring of the reaction progress was performed by ${ }^{1} \mathrm{H}$ NMR spectroscopy, using L-arabinose as a model substrate with catalyst 2 (Figure 4). The results show that the conversion of $L$ arabinose into $L$-arabinoic acid is very fast at the initial stages and then slows down and proceeds slowly. For instance, yields are higher than $50 \%$ after $4 \mathrm{~h}$ and after $8 \mathrm{~h}$ the yields are close to $80 \%$. This is the general trend observed in the conversion of all the sugars tested either by ${ }^{1} \mathrm{H}$ NMR spectroscopy (Figure 4) or HPLC/MS (Figure 3a) suggesting a first order reaction in catalyst.

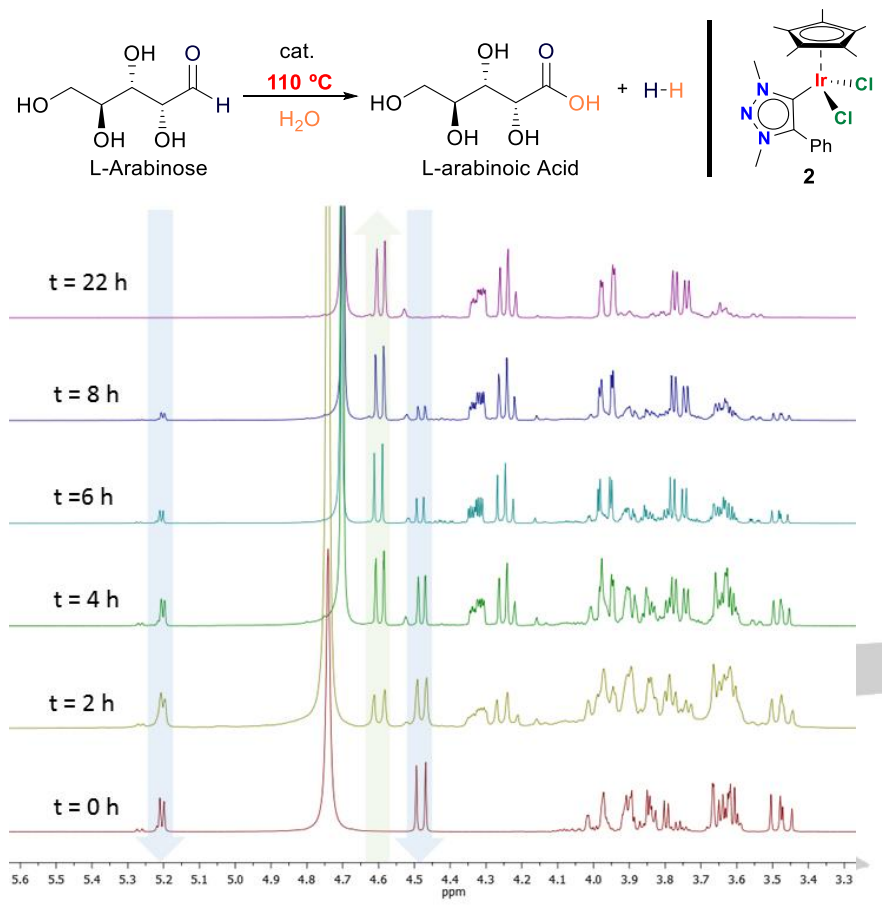

Figure 4. Time-resolved conversion monitored by ${ }^{1} \mathrm{H}$ NMR spectroscopy. LArabinose $(0.44 \mathrm{mmol})$ conversion into L-Arabinoic acid using catalyst 2 (2 mol\%) without additives in $\mathrm{H}_{2} \mathrm{O}(5 \mathrm{~mL})$. Samples were taken at appropriate time, dried under reduced pressure and dissolved in $\mathrm{D}_{2} \mathrm{O}$ for NMR analysis. Signals highlighted in green are diagnostic for determining yields, and resonances highlighted in blue for conversions.

\section{Mechanistic investigations}

In order to gain mechanistic insight into the conversion of sugars we first addressed the chemical speciation of iridium complexes in water using pre-catalyst 2 as representative complex. Catalyst 2 is soluble in water and forms an orange solution. The solubility of $\mathbf{2}$ in water is promoted by the polar nature of the triazolylidene ligand and a facile chloride-water ligand exchange at iridium (Scheme 1) as identify by the chemical speciation determined from ESI-MS and NMR spectroscopy. ${ }^{[33]}$ Aqueous solutions of 2 were stirred and aliquots were extracted at different time intervals, diluted with water to a final concentration of $5 \times 10^{-4} \mathrm{M}$ (based on the initial Ir concentration), and directly introduced to the mass spectrometer. The ESI-MS of 2 in water (Figure 5) shows two intense signals containing the hydroxo-ligated species $\left[\mathrm{Cp}^{*} \operatorname{Ir}(\operatorname{trz})(\mathrm{OH})\right]^{+}\left(\mathrm{m} / \mathrm{z}\right.$ 518.2) and $\left[\mathrm{Cp}^{*} \operatorname{Ir}(\operatorname{trz})(\mathrm{OH})\left(\mathrm{OH}_{2}\right)\right]^{+}$at $\mathrm{m} / \mathrm{z}$ 536.2, the latter coexisting with $\left.\left[\mathrm{Cp}^{*} \mathrm{Ir}(\operatorname{trz}) \mathrm{Cl}\right)\right]^{+}$. Even though species $\left[\mathrm{Cp}^{*} \operatorname{Ir}(\mathrm{trz})(\mathrm{OH})\left(\mathrm{OH}_{2}\right)\right]^{+}$and $\left[\mathrm{Cp}^{*} \operatorname{Ir}(\operatorname{trz}) \mathrm{Cl}\right]^{+}$overlap in the $\mathrm{MS}$, they could be unambiguously identified on the basis of their distinctive collision induced dissociation (CID) spectra (Figure
S54). In the lower $\mathrm{m} / \mathrm{z}$ region, we also observed doubly-charged species of formula $\left[\mathrm{Cp}^{*} \operatorname{Ir}(\mathrm{trz})\right]^{2+}(\mathrm{m} / \mathrm{z} 250.6$, not shown) attributed to the generation of the diaqua complex $\left[\mathrm{Cp}^{*} \operatorname{Ir}(\operatorname{trz})\left(\mathrm{H}_{2} \mathrm{O}\right)_{2}\right]^{2+}$ containing labile $\mathrm{H}_{2} \mathrm{O}$ ligands that are removed upon ionisation under ESI conditions.

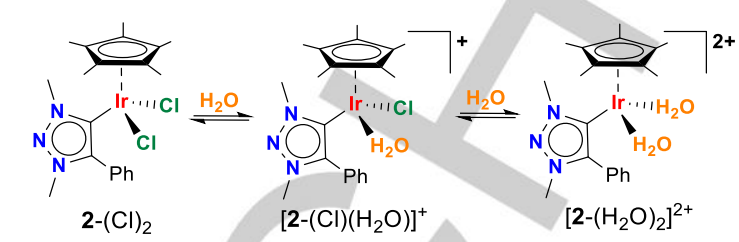

Scheme 1. Equilibrium of complex 2 in water.

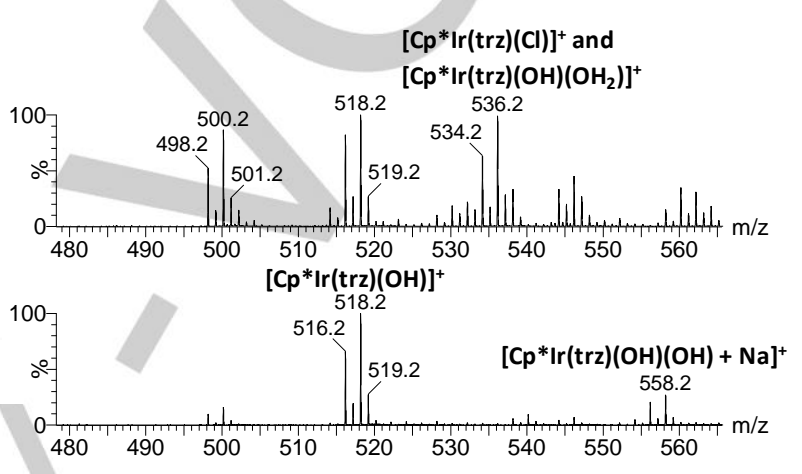

Figure 5. ESI mass spectra of complex 2 recorded in water (top) and water with $\mathrm{NaOH} 10^{-3} \mathrm{M}$ (bottom). The peak at $\mathrm{m} / \mathrm{z} 500.2$ is attributed to a product ion from species at $\mathrm{m} / \mathrm{z} 518.2$ and 536.2 .

Further support for the solvolysis equilibrium depicted in Scheme 1 is provided by recording the ESI-MS of 2 at higher $\mathrm{pH}$. Under these conditions, it is expected that iridium-bound water molecules in complexes $\left[\mathrm{Cp} * \operatorname{lr}(\operatorname{trz})\left(\mathrm{H}_{2} \mathrm{O}\right)_{2}\right]^{2+}$ are deprotonated to hydroxo ligands which are not removed under positive-mode ESI conditions. Figure 5 displays the ESI mass spectrum of aqueous solutions in the presence of $\mathrm{NaOH}\left(10^{-3} \mathrm{M}\right.$ solution). Species $\left[\mathrm{Cp}^{*} \operatorname{Ir}(\operatorname{trz})(\mathrm{OH})\right]^{+}\left(\mathrm{m} / \mathrm{z}\right.$ 518.2) and $\left[\mathrm{Cp}^{*} \operatorname{Ir}(\operatorname{trz})(\mathrm{OH})_{2}+\mathrm{Na}\right]^{+}(\mathrm{m} / \mathrm{z}$ 558.2) were detected by their $\mathrm{m} / \mathrm{z}$ values, isotopic composition and CID spectra (Figures S55, S56). Analysis of this solvolysis equilibrium by ${ }^{1} \mathrm{H}$ NMR spectroscopy using complex 2 in $\mathrm{D}_{2} \mathrm{O}$, revealed the presence of a single set of signals for the $\mathrm{Cp}^{*}$ and the triazolylidene ligand, which is consistent with fast equilibria on the NMR time scale.

Furthermore, we monitored the progress of the catalytic conversion of sugars by NMR and UV/Vis spectroscopies and by ESI-MS. The combination of these orthogonal techniques provides insights into the identity of intermediate species relevant to the mechanism. ${ }^{[34,35]}$ Notably, the conversion of sugars is accompanied by a diagnostic change of colour of the reaction solution from orange to deep-red when using complexes $1-3$. The deep-red colour is formed at initial stages and maintained during the entire catalytic reaction. This change in colour was analysed in more detail using $\mathrm{L}$-arabinose as model substrate and complex 2 as the pre-catalyst (Figures $6 a$ and $6 b$ ). The initially orange colour originates from two broad absorptions at $340 \mathrm{~nm}$ and about $400 \mathrm{~nm}$, the latter observed only as a shoulder. The spectrum of the deep-red coloured solution during conversion of L-arabinose features two distinct absorption bands at 445 and $545 \mathrm{~nm}$. 
Monitoring the reaction by ESI-MS revealed a signal at $\mathrm{m} / \mathrm{z} 501.2$, which is maintained during the course of the reaction. The mass/charge value and the simulated isotopic pattern distribution support the formation of a dicationic diiridium-hydride species (Figure $6 \mathrm{~d}$ ). Other signals confirmed the reaction progress as indicated by the observation of signals corresponding to deprotonated arabinoic acid-bound complex formulated as $\left[\mathrm{Cp}^{*} \operatorname{Ir}(\operatorname{trz})\left(\mathrm{C}_{5} \mathrm{O}_{6} \mathrm{H}_{9}\right)\right]^{+}$at $\mathrm{m} / \mathrm{z} 666.2$ (Figure $\left.6 \mathrm{~d}\right)$ and in the negative scan mode the signal attributed to deprotonated arabinoic acid at $\mathrm{m} / \mathrm{z} 165$. The presence of a hydride species was further confirmed by monitoring the catalytic reaction by ${ }^{1} \mathrm{H}$ NMR spectroscopy using L-arabinose and $10 \mathrm{~mol} \%$ of pre-catalyst 2 . The spectra showed a characteristic signal in the hydride region at $-16.8 \mathrm{ppm}$, integrating for two hydrogen nuclei. Based on these data and the ESI-MS analysis, we postulate a dimetallic species $\mathbf{5}$ as intermediate with molecular formula $\left[\mathrm{Cp}^{*}(\operatorname{trz}) \operatorname{lr}(\mu-\mathrm{H})_{2} \operatorname{Ir}(\operatorname{trz}) \mathrm{Cp}^{*}\right]^{2+}$, which contains two $\left[\mathrm{Cp}^{*} \operatorname{Ir}(\operatorname{trz})\right]$ fragments bridged by two hydride ligands. Similar diiridium-hydride species have been described before using $\mathrm{N}$-heterocyclic carbene ligands. ${ }^{[36,37]}$ In order to further characterise this species, we synthesised the diridiumhydride complex 5 as a triflate salt starting from 2 by chloride abstraction and exposure to $\mathrm{H}_{2}$ (See ESI for details). Characterisation by ESI-MS and ${ }^{1} \mathrm{H}$ NMR spectroscopy showed the same ion fragment $(\mathrm{m} / \mathrm{z} 501.2)$ and isotopic distribution and a hydride resonance at $-16.8 \mathrm{ppm}$, in excellent agreement with the data of the intermediate formed during the catalytic reaction. The molecular structure of complex $\mathbf{5}$ was unambiguously elucidated by single crystal X-ray diffraction (Figure 6c). Most strikingly, the isolated complex $\mathbf{5}$, is catalytically competent in the dehydrogenative transformation of $\mathrm{L}$-arabinose and achieves activity comparable to those observed with complex 2 , suggesting an identical or at least closely related catalytically active species. In addition, the UV/Vis spectrum of $\mathbf{5}$ in water shows two characteristic bands at 445 and $545 \mathrm{~nm}$, commensurate with the diagnostic features of the catalytic solution (Fig. 7, see also discussion above). These data therefore suggest that the diiridium-hydride complex $\mathbf{5}$ is a relevant species in the reaction mechanism as an off-cycle catalyst resting state. Most probably, cleavage of the diiridium-hydride species provides an iridium monohydride intermediate, which is able to bind the carbohydrate or water and subsequently release a carbohydrate/water proton and the metal-bound hydride as $\mathrm{H}_{2}$.
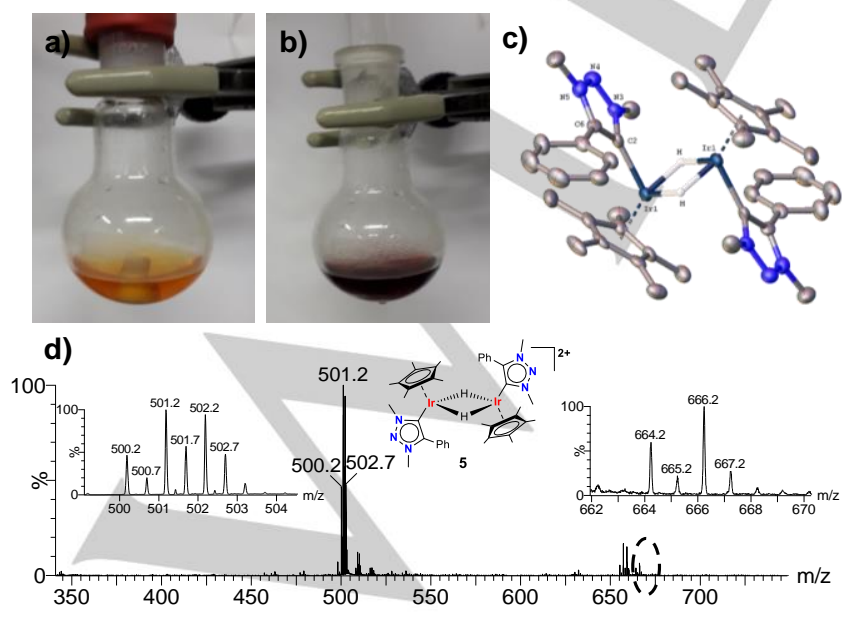

Figure 6. (a) Initial orange solution in $\mathrm{H}_{2} \mathrm{O}$ of $\mathrm{L}$-arabinose with catalyst 2 and (b) characteristic deep-red solution after $30 \mathrm{~min}$. at $110^{\circ} \mathrm{C}$. (c) ORTEP structure from single crystal X-ray diffraction of complex 5 (hydrogen atoms except hydrides and counterions $\left(2 \mathrm{CF}_{3} \mathrm{SO}_{3}{ }^{-}\right)$omitted for clarity). (d) ESI-MS of the deep-red solution showing a base peak at $501.2 \mathrm{~m} / \mathrm{z}$ that fits with $\left[\mathrm{Cp}^{*}(\operatorname{trz}) \operatorname{lr}(\mu-\right.$ $\left.\mathrm{H})_{2} \operatorname{lr}(\operatorname{trz}) \mathrm{Cp}^{*}\right]^{2+}$ and a minor peak (m/z 666.2) due to the deprotonated arabinoic acid-bound complex formulated as $\left[\mathrm{Cp}^{*} \mathrm{Ir}(\operatorname{trz})\left(\mathrm{C}_{5} \mathrm{O}_{6} \mathrm{H}_{9}\right)\right]^{+}$.

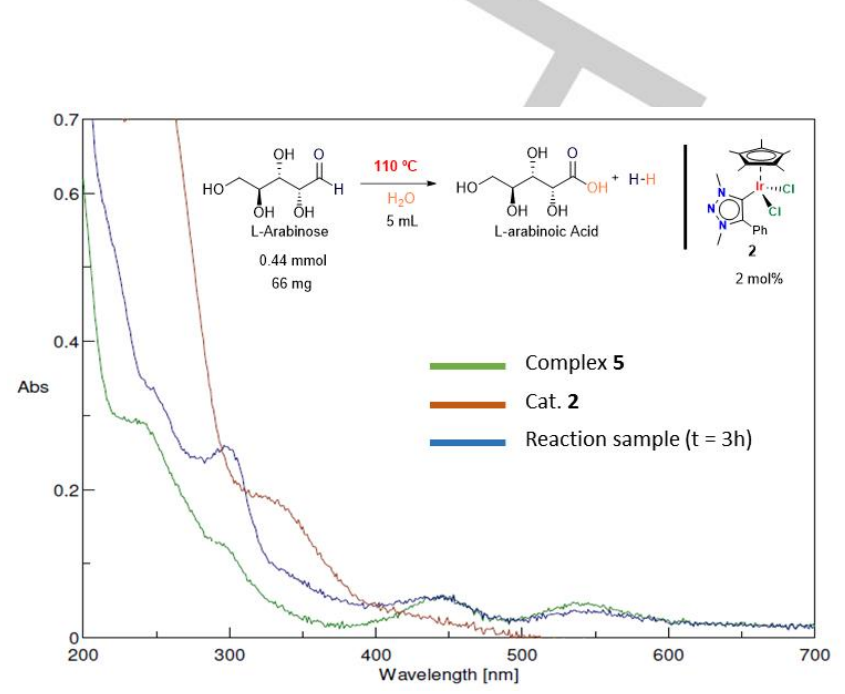

Figure 7. UV/vis spectra of the solutions $\left(\mathrm{H}_{2} \mathrm{O}\right)$ from the catalytic conversion of $\mathrm{L}$-arabinose. The bands at $445 \mathrm{~nm}$ and $545 \mathrm{~nm}$ are identical for the catalytic reaction (blue line) and for the independently prepared diiridium-hydride species 5 (green line)

A plausible mechanism for the conversion of sugars into sugar acids is proposed based on previous results ${ }^{[29]}$ and complemented by the new experimental evidence from this work (Scheme 2). Iridium complexes of general formula $\left[\mathrm{Cp}^{*} \operatorname{IrL}(\mathrm{Cl})_{2}\right](\mathrm{L}$ $=\mathrm{NHC}$ or triazolylidene undergo water/halide ligand exchange forming the aqua complexes that are the active catalytic species (Scheme 1). The labile $\mathrm{H}_{2} \mathrm{O}$ ligands are substituted by Larabinose most probably in a chelate coordination via the carbonyl and a hydroxyl group (A). Such chelation may rationalise the selectivity of the oxidation, which does not affect any of the primary or secondary alcohol units. Intermediate A featuring triazolylidene as ancillary ligand was not observed by ESI-MS; however, for the NHC pre-catalyst 1 and glucose, intermediate $\mathrm{A}$ was readily observed. The enhanced stability of the sugar-bound intermediate $\mathrm{A}$ in the case of the NHC-based catalyst correlates with the reduced catalytic activity of this complex towards the sugar acid formation. ${ }^{[38]}$ The coordinated L-arabinose undergoes nucleophilic attack by water at the aldehyde, producing a gemdiol species (B). These species have been postulated as key intermediates in the conversion of alcohols or aldehydes to carboxylic acids or esters in aqueous media. ${ }^{[39-48]}$ The gem-diol species releases a solvated proton, forms an iridium-hydride by $\beta$-hydride elimination and delivers the $L$-arabinoic acid product $(C, D)$. The iridium-hydride species is in equilibrium with the diiridium-hydride (5) which corresponds to the catalyst resting state. In the final stage, the iridium hydride is protonated by the previously released proton to form (E). We speculate that this protonation step is greatly accelerated by the triazolylidene ligand due to the potentially basic N2 site of this ligand, ${ }^{[32,49]}$ which enables an intramolecular and hence fast proton shuttle mechanism from N2 to the iridium-bound hydride. Such intramolecular proton transfer is not feasible with $\mathrm{NHC}$ complexes and may therefore rationalise the need for a strong acid as 
additive with those ligands, but not with triazole-derived carbenes. Formation of $(E)$ induces the release of molecular hydrogen and regeneration of the initial diaqua species $\left[2-\left(\mathrm{H}_{2} \mathrm{O}\right)_{2}\right]^{2+}$.

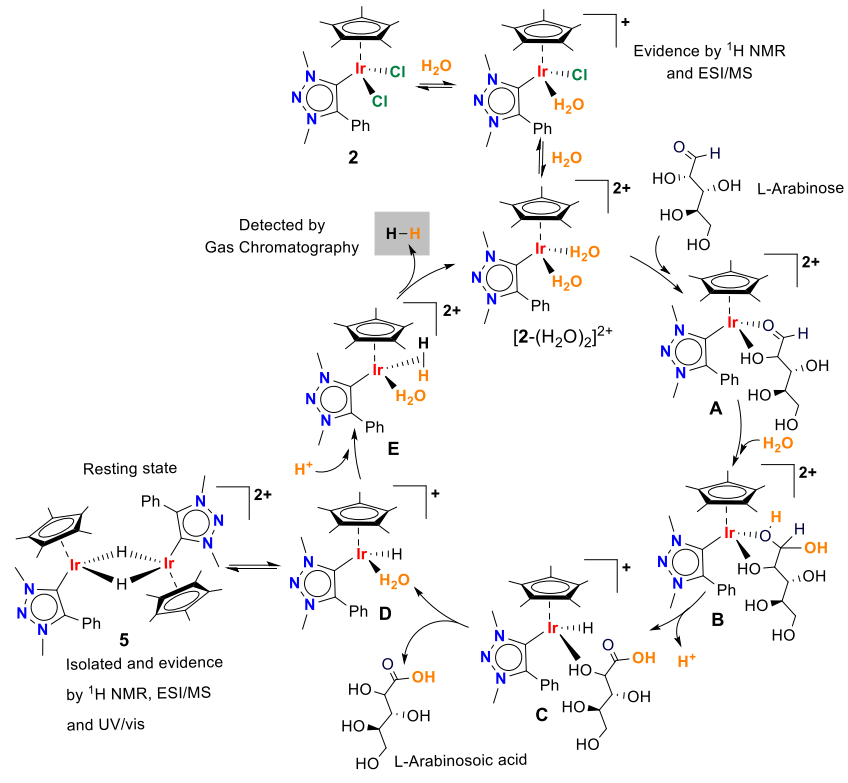

Scheme 2. Mechanistic proposal for the conversion of sugars to sugar acids and hydrogen.

\section{Conclusions}

Iridium complexes bearing triazolylidene ligands are efficient catalysts for the conversion of sugars into sugar acids without additives and using water as solvent. This transformation produces molecular hydrogen as a valuable by-product along with the selective formation of sugar acids. The conversion of sugars represents an interesting biomass transformation for the production of initial platform chemicals in a sustainable manner. The reaction is highly selective and does not require purification of the sugar acid products. Moreover, the catalysts are highly promiscuous and convert a variety of carbohydrate substrates, which contrasts the typically highly substrate-specific mode of operation of enzymes. Noticeably, high conversion and selectivity proceeds without any additional acid using triazolylidene complexes, which is a common requirement for sugar dehydrogenation in the presence of its $\mathrm{NHC}$ congeners. Mechanistic studies support the formation of a diiridium-hydride as catalyst resting state in the conversion of sugars to sugar acids. These results provide useful guidelines for further optimisation of this valuable biomass transformation.

\section{Experimental Section}

General details. Catalysts 1 - 4 were synthesised according to reported procedures. ${ }^{[50-52]}$ D-glucose (99 \%), D-gluconic acid (50\% aq. sol), Dribose (98\%), D-xylose (99\%), L-arabinose (99\%), D-mannose (99\%), DGalactose (98\%) and 2-deoxy-D-glucose $(99 \%)$ were purchased from commercial suppliers and used as received. HPLC-grade water was obtained from distilled water passed through a Milli-Q water purification system. Nuclear magnetic resonance (NMR) spectra were recorded on Bruker spectrometers operating at $400 \mathrm{MHz}\left({ }^{1} \mathrm{H}\right.$ NMR $)$ and $100 \mathrm{MHz}$ $\left({ }^{13} \mathrm{C}\left\{{ }^{1} \mathrm{H}\right\} \mathrm{NMR}\right.$ ) respectively, and referenced to $\mathrm{SiMe}_{4}(\delta$ in ppm and $\mathrm{J}$ in $\mathrm{Hz}$ ). NMR spectra were recorded at room temperature with the appropriate deuterated solvent. UV/vis spectra were recorded on a Jasco spectropolarimeter at room temperature using MiliQ water as solvent. Hydrogen was analysed using gas chromatography with a GS-MOL 15 meters column ID $0.55 \mathrm{~mm}$ TCD from J\&W Scientific, using $\mathrm{N}_{2}$ as carrier gas.

High Resolution Mass Spectrometry (HRMS) and Collision Induced Dissociation (CID) experiments. HRMS studies were conducted on a QTOF Premier instrument with an orthogonal Z-spray-electrospray interface (Waters, Manchester, UK) operating in the $\mathrm{V}$-mode at a resolution of ca. 10000 (FWHM). The drying and cone gas was nitrogen set to flow rates of 300 and $30 \mathrm{~L} / \mathrm{h}$, respectively. A capillary voltage of $3.5 \mathrm{kV}$ was used in the positive ESI(+) scan mode. The cone voltage was adjusted to a low value (typically $\mathrm{Uc}=5-15 \mathrm{~V}$ ) to control the extent of fragmentation in the source region. Chemical identification of the Ir-containing species was facilitated by the characteristic isotopic pattern at natural abundance of Ir and it was carried out by comparison of the isotope experimental and theoretical patterns using the MassLynx 4.1 software. Sample preparation was carried out as follows: i) for aqueous speciation studies, aqueous solutions of pre-catalysts were stirred and aliquots were extracted at the required time intervals and ii) for the study of the progress of the catalytic reaction, aqueous solutions of pre-catalysts were stirred under catalytic conditions and aliquots were extracted at the required time intervals. In both cases, samples were diluted with water to a final concentration of $5 \mathrm{x}$ $10^{-4} \mathrm{M}$ (based on the initial Ir concentration) and directly introduced to the mass spectrometer. For CID experiments, the cations of interest were mass-selected using the first quadrupole (Q1) and interacted with argon in the $T$-wave collision cell at variable collision energies $\left(E_{\text {laboratory }}=3-15 \mathrm{eV}\right)$. The ionic products of fragmentation were analysed with the time-of-flight analyser. The isolation width was $1 \mathrm{Da}$ and the most abundant isotopomer was mass-selected in the first quadrupole analyser.

General procedure for catalytic experiments. In a typical reaction, iridium catalyst $(2 \mathrm{~mol} \%)$ was added to a sugar solution $(0.44 \mathrm{mmol})$ in deionised $\mathrm{H}_{2} \mathrm{O}(5 \mathrm{~mL})$. The reaction vessel was connected to a reflux condenser and was introduced in a pre-heated oil bath at $110^{\circ} \mathrm{C}$ for the appropriate time (standard time 20h). Reaction monitoring was carried out following two methodologies: for the quantification of glucose/gluconic acid, a previously described method based on reverse-phase UHPLC coupled to ESI-MS/MS was used. For the rest of sugars and sugar acids, different aliquots $(400 \mu \mathrm{L})$ were directly extracted from the Schlenk tube with a syringe. The solvent was removed under reduced pressure and the residue was redissolved in $\mathrm{D}_{2} \mathrm{O}$ for ${ }^{1} \mathrm{H}$ NMR analysis. At the end of the reaction, the solvent was evaporated and the crude product was analysed by ${ }^{1} \mathrm{H}$-NMR spectroscopy without further purification. In the case of $D$ gluconic and $\mathrm{D}$-xylonic acids the $\mathrm{pH}$ was adjusted to 12 by adding $\mathrm{NaOH}$ for NMR characterisation.

Procedure for hydrogen identification. After $4 \mathrm{~h}$ reaction of a general catalytic experiment, a $15 \mathrm{~mL}$ sample of the generated gas was collected with a gastight syringe and the hydrogen content was qualitative analysed by gas chromatography using a TCD detector.

\section{Acknowledgements}

The authors thank the financial support from MICIU/AEI/FEDER (RTI2018-098237-B-C22) and Universitat Jaume I (UJI-B201823). P. Borja thanks the Universitat Jaume I for a postdoctoral grant. We acknowledge generous support from the European Commission for a Marie Skłodowska Curie Individual Fellowship to J. P. Byrne (Grant 749549) and from the European Research Council to M. Albrecht (CoG 615653). The authors are very 
grateful to the 'Servei Central d'Instrumentació Científica (SCIC)' of the Universitat Jaume I.

\section{Notes}

Supporting information. Catalytic reaction monitoring, characterisation and HPLC-MS/MS method for the quantification of sugars and sugar acids. CCDC 1969933 contains the supplementary crystallographic data for this paper. These data are provided free of charge by The Cambridge Crystallographic Data Centre.

\section{Conflict of interest}

The authors declare no conflict of interest.

Keywords: sugars • sugar acids • iridium • biomass • dehydrogenation $\cdot$ catalysis in water

[1] A. Corma, S. Iborra, A. Velty, Chem. Rev. 2007, 107, 2411-2502.

[2] M. Besson, P. Gallezot, C. Pinel, Chem. Rev. 2014, 114, 1827-1870.

[3] R. A. Sheldon, Green Chem. 2014, 16, 950-963.

[4] M. Yabushita, H. Kobayashi, A. Fukuoka, Appl. Catal. B Environ. 2014, 145, 1-9.

[5] P. Gallezot, Green Chem. 2007, 9, 295-302.

[6] P. Gallezot, ChemSusChem 2008, 1, 734-737.

[7] P. Gallezot, Chem. Soc. Rev. 2012, 41, 1538-1558.

[8] J. He, H. Li, S. Saravanamurugan, S. Yang, ChemSusChem 2019, 12, 347-378.

[9] H. Choudhary, S. Nishimura, K. Ebitani, Appl. Catal. B Environ. 2015, 162, 1-10.

[10] L. T. Mika, E. Cséfalvay, Á. Németh, Chem. Rev. 2018, 118, 505-613.

[11] M. J. Climent, A. Corma, S. Iborra, Green Chem. 2011, 13, 520-540.

[12] M. J. Climent, A. Corma, S. Iborra, Chem. Rev. 2011, 111, 1072-1133.

[13] A. Mirescu, U. Prüße, Appl. Catal. B Environ. 2007, 70, 644-652.

[14] B. C. E. Makhubela, J. Darkwa, Johnson Matthey Technol. Rev. 2018, 62, 4-31.

[15] N. Mager, N. Meyer, A. F. Léonard, N. Job, M. Devillers, S. Hermans, Appl. Catal. B Environ. 2014, 148-149, 424-435.

[16] C. Chatterjee, F. Pong, A. Sen, Green Chem. 2015, 17, 40-71.

[17] P. J. Deuss, K. Barta, J. G. de Vries, Catal. Sci. Technol. 2014, 4, 1174 1196.

[18] J. Esteban, P. Yustos, M. Ladero, Catalysts 2018, 8, 637-676.

[19] P. Bhaumik, P. L. Dhepe, in RSC Green Chem., 2016, pp. 1-53.

[20] A. D. Sutton, J. K. Kim, R. Wu, C. B. Hoyt, D. B. Kimball, L. A. Silks, J. C. Gordon, ChemSusChem 2016, 9, 2298-2300.

[21] B. T. Kusema, D. Y. Murzin, Catal. Sci. Technol. 2013, 3, 297-307.

[22] S. Ramachandran, P. Fontanille, A. Pandey, C. Larroche, Food Technol. Biotechnol. 2006, 44, 185-195.

[23] R. H. Crabtree, Handbook of Green Chemistry, Green Catalysis, Heterogeneous Catalysis, WILEY-VCH Verlag, 2009.

[24] T. Thananatthanachon, T. B. Rauchfuss, ChemSusChem 2010, 3, 11391141.

[25] L.-A. Schaper, S. J. Hock, W. A. Herrmann, F. E. Kühn, Angew. Chem. Int. Ed. 2013, 52, 270-289.

[26] H. D. Velazquez, F. Verpoort, Chem. Soc. Rev. 2012, 41, 7032-7060.

[27] S. De, A. Udvardy, C. E. Czégéni, F. Joó, Coord. Chem. Rev. 2019, 400, 213038-213069.

[28] Á. Vivancos, C. Segarra, M. Albrecht, Chem. Rev. 2018, 118, 9493-9586.

[29] P. Borja, C. Vicent, M. Baya, H. García, J. A. Mata, Green Chem. 2018, 20, 4094-4101.

[30] J. A. Woods, R. Lalrempuia, A. Petronilho, N. D. McDaniel, H. MüllerBunz, M. Albrecht, S. Bernhard, Energy Environ. Sci. 2014, 7, 2316-
2328.

[31] A. Petronilho, J. A. Woods, H. Mueller-Bunz, S. Bernhard, M. Albrecht, Chem. Eur. J. 2014, 20, 15775-15784.

[32] Y. Tulchinsky, M. A. Iron, M. Botoshansky, M. Gandelman, Nat. Chem. 2011, 3, 525-531.

[33] A. Petronilho, A. Llobet, M. Albrecht, Inorg. Chem. 2014, 53, 1289612901.

[34] R. Theron, Y. Wu, L. P. E. Yunker, A. V. Hesketh, I. Pernik, A. S. Weller, J. S. McIndoe, ACS Catal. 2016, 6, 6911-6917.

[35] S. L. Scott, ACS Catal. 2019, 9, 4706-4708.

[36] F. Hanasaka, K. Fujita, R. Yamaguchi, Organometallics 2005, 24, 34223433.

[37] M. C. Lehman, J. B. Gary, P. D. Boyle, M. S. Sanford, E. A. Ison, ACS Catal. 2013, 3, 2304-2310.

[38] J. Wassenaar, E. Jansen, W.-J. van Zeist, F. M. Bickelhaupt, M. A. Siegler, A. L. Spek, J. N. H. Reek, Nat. Chem. 2010, 2, 417-421.

[39] E. Balaraman, E. Khaskin, G. Leitus, D. Milstein, Nat. Chem. 2013, 5, 122-125.

[40] R. Kawahara, K. Fujita, R. Yamaguchi, J. Am. Chem. Soc. 2012, 134, 3643-3646.

[41] M. Trincado, D. Banerjee, H. Grützmacher, Energy Environ. Sci. 2014, 7, 2464-2503.

[42] D. Ventura-Espinosa, C. Vicent, M. Baya, J. A. Mata, Catal. Sci. Technol. 2016, 6, 8024-8035.

[43] T. Zweifel, J.-V. Naubron, H. Grützmacher, Angew. Chem. Int. Ed. 2009, $48,559-563$

[44] C. Gunanathan, D. Milstein, Science 2013, 341, 1229712-1229712.

[45] H. Li, M. B. Hall, J. Am. Chem. Soc. 2014, 136, 383-95.

[46] R. E. Rodríguez-Lugo, M. Trincado, M. Vogt, F. Tewes, G. SantisoQuinones, H. Grützmacher, Nat. Chem. 2013, 5, 342-347.

[47] C. Vicent, D. G. Gusev, ACS Catal. 2016, 6, 3301-3309.

[48] D. Spasyuk, C. Vicent, D. G. Gusev, J. Am. Chem. Soc. 2015, 137, 3743-3746.

[49] B. K. Keitz, J. Bouffard, G. Bertrand, R. H. Grubbs, J. Am. Chem. Soc. 2011, 133, 8498-8501.

[50] X.-Q. Xiao, G.-X. Jin, J. Organomet. Chem. 2008, 693, 3363-3368.

[51] A. Petronilho, M. Rahman, J. A. Woods, H. Al-Sayyed, H. Müller-Bunz, J. M. Don MacElroy, S. Bernhard, M. Albrecht, Dalton Trans. 2012, 41, 13074-13080.

[52] R. Pretorius, J. Olguín, M. Albrecht, Inorg. Chem. 2017, 56, 1241012420. 


\section{Entry for the Table of Contents}
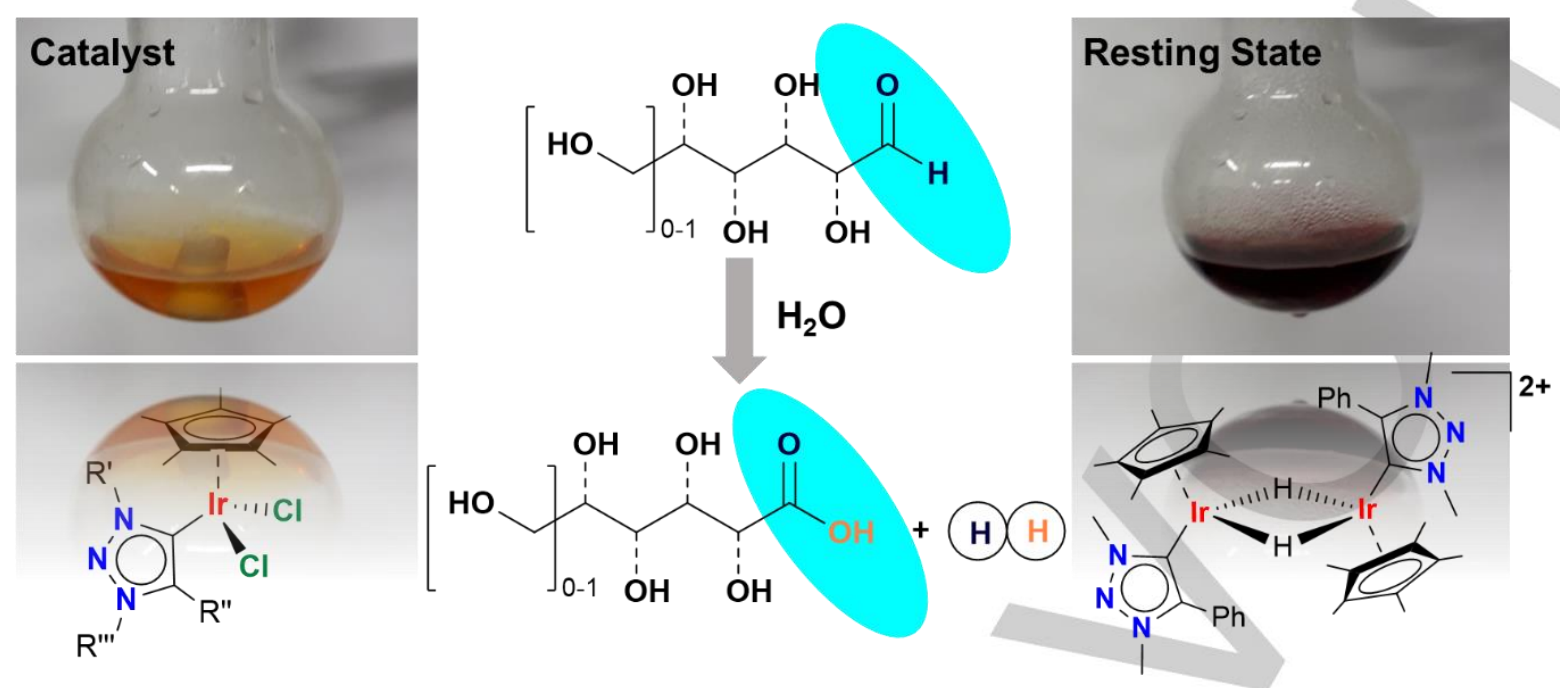

A sustainable catalytic process for the conversion of sugars into sugar acids using water as solvent without additives.

Institute Twitter username: @inam_uji

Researcher Twitter username: @jose_mata_uji

Researcher Twitter username: @albrecht_lab 